\title{
BORGES, DELEUZE E O TEMPO
}

Paula Marchesini é formada em filosofia pela PUC-Rio e atualmente cursa o Mestrado em Literatura Brasileira, na mesma instituição. Em sua pesquisa, analisa a questão do tempo em diferentes textos canônicos de épocas diversas, buscando compreender de que maneira a relação do homem com o tempo cria a necessidade de produzir textos literários. Contato: paulamsmendes@gmail.com.

\section{RESUMO:}

O presente trabalho estabelece um paralelo entre o conceito de tempo deleuziano, discutido no livro O Tempo Não-Reconciliado, de Peter Pál Pelbart, e o tempo como tratado por Borges nos contos Nova Refutação do Tempo e História da Eternidade.

\begin{abstract}
:
The present text establishes a parallel between the deleuzian concept of time, discussed in the book O Tempo Não-Reconciliado, by Peter Pál Pelbart, and time as treated by Borges in the short stories "New Refutation of Time" and "History of Eternity".
\end{abstract}

No Prólogo de O Tempo Não-Reconciliado, Peter Pál Pelbart contrapõe o filósofo ao cientista, dizendo que, ao primeiro, não se impõe uma única imagem de tempo, já que ele é capaz de admitir um tempo múltiplo, caótico e policrônico, bem como de afirmar a existência de todos os mundos possíveis - incompossíveis para Leibniz - em um mesmo mundo.

Logo mais, na Introdução, o autor sugere "uma forte inspiração borgesiana" (Pelbart, 2004, XIX) em Deleuze, por sua maneira de retomar seus principais temas, sempre enfatizando aspectos distintos do problema e ligando-se a novos autores. Deleuze, como Borges, apresenta uma temática temporal própria e labiríntica, como sugere Pelbart, quando coloca que:

"(...) em Deleuze, ao invés de uma linha do tempo, temos um emaranhado do tempo; em vez de um fluxo do tempo, veremos surgir uma massa de tempo; em lugar de um rio do tempo, um labirinto do tempo. Ou ainda, não mais um círculo do tempo, porém um turbilhão, já não uma ordem do tempo, mas uma variação infinita, nem mesmo uma forma do tempo, mas um tempo informal, plástico. Com isto, estaríamos mais próximos, sem dúvida, de um tempo da alucinação do que de uma consciência do tempo." (Pelbart, 2004, XXI)

A abordagem do tempo em Deleuze é recorrente, ainda que se dê esparsa e fragmentariamente. Em seu primeiro artigo sobre Bergson, ele define a duração como "o que difere de si" (Deleuze, 1956, 88); tal definição é importante se considerarmos que toda a questão do tempo em Deleuze se desenrola sobre o seu conceito de diferença.

Outro conceito importante, ao qual Pelbart chama a atenção, é o de rizoma, que aparece em Mil Platôs e ajuda a compreender a lógica da multiplicidade. O rizoma desafia a lógica tradicional, 0 pensamento 
metódico, ordenado em início, meio e fim, e insiste na conexão entre todos os pontos do sistema, na desordem fundamental da filosofia.

A concepção deleuziana de tempo filosófico é também importante para compreendermos sua abordagem do tema. Em O Que é Filosofia?, ele o define como:

"um grandioso tempo de coexistência, que não exclui o antes e o depois, mas os superpõe numa ordem estratigráfica (...) A vida dos filósofos, e o mais exterior de sua obra, obedece a leis de sucessão ordinária; mas seus nomes próprios coexistem e brilham, seja como pontos luminosos que nos fazem repassar pelos componentes de um conceito, seja como os pontos cardeais de uma camada ou de uma folha que não deixam de visitar-nos, como estrelas mortas cuja luz é mais viva do que nunca. A filosofia é devir, não história; ela é coexistência de planos, não sucessão de sistemas." (Deleuze, 1991, 58-59)

Paralelo e, em alguns pontos, superposto ao labirinto de Deleuze, encontramos o de Borges; como o filósofo, escritor e ensaísta esteve assombrado pelas mais diversas visões do tempo. Em "A Nova Refutação do Tempo", ele quer negar o conceito, baseando-se, principalmente, no idealismo de Berkeley. No Prólogo a História da Eternidade, queixa-se: "Como pude não sentir que a eternidade, almejada com amor por tantos poetas, é um artifício esplêndido que nos livra, mesmo que de maneira fugaz, da intolerável opressão da sucessividade?" (Borges, 2001, 9)

Portanto, estabelecer uma relação entre o conceito de tempo de Borges e o de Deleuze é enriquecedor sob diversos aspectos, nos ajudando a pensar, não apenas o próprio conceito de tempo, mas o processo criativo de Borges, a maneira singular do pensamento deleuziano, bem como a ligação entre arte e filosofia.

\section{A refutação do tempo em Borges e o tempo múltiplo de Deleuze}

Tanto em "Nova Refutação do Tempo", quanto em "História da Eternidade", observamos a profunda desconfiança de Borges com relação ao conceito de tempo.

No primeiro texto, ele coloca que, ao longo de toda sua vida, pressentiu uma refutação do tempo, que está presente em praticamente todos os seus livros, mas que jamais fundamentou satisfatoriamente. Empreende, portanto, uma tentativa de justificá-la baseando-se no idealismo de Berkeley e no princípio dos indiscerníveis de Leibniz.

De acordo com o idealismo, todos os nossos pensamentos, percepções, paixões e idéias são dependentes da mente. Não há, portanto, objetos exteriores à mente, nem um eu exterior às percepções da mente, sendo o sujeito mera sucessão de atos imaginários e impressões errantes. No entanto, Borges aponta para a incoerência da idéia de sucessão onde foram refutados o espírito, a matéria e o espaço. Ele escreve: 
"Imaginemos um presente qualquer. Em uma das noites do Mississipi, Huckleberry Finn acorda; a jangada, perdida na escuridão parcial, segue rio abaixo; faz, talvez, um pouco de frio. Huckleberry Finn reconhece o manso rumor incansável da água; abre os olhos com negligência; vê um vago número de estrelas, vê uma linha indistinta que são as árvores; em seguida, mergulha no sono imemorial como em uma água escura. A metafísica idealista declara que acrescentar a essas percepções uma substância material (o objeto) e uma substância espiritual (o sujeito) é temerário e inútil; eu afirmo que não menos ilógico é pensar que são termos de uma série cujo princípio é tão inconcebível quanto seu fim. Acrescentar ao rio e à margem percebidos por Huck a noção de outro rio substantivo de outra margem, acrescentar outra percepção a essa rede imediata de percepções é, para o idealismo, injustificável; para mim, não é menos injustificável acrescentar uma precisão cronológica: o fato, por exemplo, de o evento ter ocorrido na noite de 7 de junho de 1849, entre quatro e dez e quatro e onze. Em outras palavras: nego, com argumentos do idealismo, a vasta série temporal que o idealismo admite. Hume negou a existência de um espaço absoluto, em que cada coisa tem seu lugar; eu, a de um único tempo, em que todos os fatos se encadeiam. Negar a coexistência não é menos árduo que negar a sucessão." (Borges, 1999, 155)

Além da sucessividade, ele nega também a simultaneidade. Para ele, cada estado que vivemos é absoluto e incapaz de modificar os outros. Não há dois eventos que aconteçam "ao mesmo tempo", pois o tempo não é ubíquo, e só existe o estado de cada um que vive seu próprio momento. Só há portanto o presente, que está sempre sendo percebido por alguém e que dura tanto quanto a história do universo - história que não passa de mera coleção ideal de momentos. O futuro é tão impensável quanto o passado, e cada homem vive seu tempo, distinto do tempo de todos os outros homens.

Borges refuta o tempo como "série temporal" e, apoiando-se no princípio dos indiscerníveis de Leibniz, admite a repetição de um momento na vida do indivíduo como sendo a vivência do mesmo momento. Ele coloca que a vida humana é, basicamente, constituída por tautologias e que os pensamentos recorrentes, ainda que levemente distintos cada vez que ocorrem, são sempre o mesmo. Assim, um único termo repetido é suficiente para desmantelar a série temporal.

Borges concebe um mundo sem pluralidade, em que cada homem é todo o mundo e vale tanto quanto todos os homens. Ele escreve que "As ruidosas catástrofes gerais - incêndios, guerras, epidemias, são uma só dor, ilusoriamente multiplicada em muitos espelhos." (Borges, 1999, 157)

No segundo texto, "História da Eternidade", Borges resgata a refutação eleata do movimento e do tempo e relembra a dificuldade de sincronizar o tempo individual de cada um com o tempo geral das matemáticas. Apresenta também sua própria teoria da eternidade, transcrevendo seu texto "Sentirse en Muerte", também presente na "Nova Refutação do Tempo", em que descreve sua caminhada por um pequeno 
vilarejo perto do local onde passara a infância, defendendo que aquele momento era precisamente o mesmo de 30 anos atrás:

\begin{abstract}
"Essa pura representação de fatos homogêneos - noite em serenidade, paredezinha límpida, cheiro provinciano de madressilva, barro fundamental - não é apenas idêntica à que houve nessa esquina há tantos anos; é, sem semelhanças nem repetições, a mesma. O tempo, se podemos intuir essa identidade, é uma ilusão: a indiferenciação e a inseparabilidade de um momento de seu aparente ontem e de outro de seu aparente hoje bastam para desintegrá-lo." (Borges, 2001, 32-33)
\end{abstract}

Ao tempo refutado de Borges, podemos contrapor as diversas imagens do conceito oferecidas por Deleuze, que compõem um tempo múltiplo, labiríntico e extremamente complexo.

Juntamente com uma imagem dogmática do pensamento, Deleuze recusou uma imagem do tempo que ele denominou circular, que se refere a um tempo reconciliado consigo mesmo, uma estrutura profunda centrada no presente, que se movimenta de maneira orientada. É o tempo da Representação, do Mesmo, ao qual Deleuze opôs um tempo autônomo, desgarrado do Presente e do Passado enquanto centros de tempo, retirado dos eixos. Este tempo liberado do movimento continua, no entanto, paradoxalmente submetido à flecha temporal e à lei da causalidade que lhe dá direção.

Toda a profundidade ontológica alcançada por Deleuze foi atingida pela recusa às monocentragens. Assim ele concebeu um tempo como Multilpicidade, uma Massa de tempo que é um plano de coexistências virtuais no qual o tempo se conserva como virtualidade a ser atualizada das formas mais diversas. O Acontecimento se daria, portanto, nesse plano transcendental e virtual, em um tempo aiônico, sendo suficiente e eterno.

O rizoma temporal, em Deleuze, o tempo amorfo do Acontecimento, se opõe, portanto, ao tempo circular, da História. No entanto, há uma outra imagem de círculo, o Círculo do Outro, que faz retornar, ao invés do Mesmo, a Diferença, fazendo com que o tempo atinja sua potência última, sua capacidade máxima de afirmar o devir, o acaso e a contingência. É o Tempo como Diferença, do eterno retorno seletivo, que leva a Variação à sua máxima potência.

Concebendo o Tempo como Diferença, Deleuze concebe o Futuro como iminência no seio do devir ou diferença emergente e não como um presente que está adiante do nosso.

Como coloca Pelbart, Deleuze demonstrou freqüentemente que a criação de conceitos pede um plano de imanência - anterior a eles e sobre o qual são construídos - que implica uma experimentação cega e irracional, semelhante à do sonho e da loucura. O modo como cada filósofo concebeu o tempo indica que tipo de plano de imanência ele erigiu. Assim, Platão construiu seu conceito de tempo sobre o plano de imanência clássico, do pensamento como verdade, vendo-o como imagem móvel da eternidade. A reminiscência platônica foi substituída pelo inatismo cartesiano e este pelo a priori kantiano. O plano de imanência moderno, do 
pensamento como criação e movimento infinito (não atribuível a um sujeito), pediria um novo tempo, a ser concebido.

Esse novo tempo deveria desprender-se de qualquer "vontade de verdade" e liberar imagens múltiplas, afirmando-se como variação. As imagens de tempo exploradas por Deleuze quiseram dar conta não só da variação do tempo, mas também da do pensamento. O tempo aparecerá, de fato, como a matéria mais íntima do pensamento, o seu Fora que o força ao seu limite.

O tempo deleuziano situa-se, desta forma, além do limite do pensamento, conspirando contra a verdade, tornando compossíveis presentes e passados incompossíveis e afirmando a potência criadora e libertadora do falso. Torna, portanto, o verdadeiro e o falso indiscerníveis, derrubando as barreiras entre real e imaginário.

Esse espaço ocupado pelo tempo (o Fora) está ligado a toda a dificuldade do pensamento deleuziano. Querendo ir além do limite, trabalhando incansavelmente com a Diferença, sem nos dar a segurança de qualquer constância, o filósofo se expressa por figuras opostas e contraditórias, monta sua sede na própria Variação, forçando-nos também aos nossos limites. Em Diferença e Repetição, ele enfatiza que:

"(...) os conceitos designam tão-somente possibilidades. Falta-Ihes uma garra, que seria a da necessidade absoluta, isto é, de uma violência original feita ao pensamento, de uma estranheza, de uma inimizade, a única a tirá-lo de seu estupor natural ou de sua eterna possibilidade: tanto quanto só há pensamento involuntário, suscitado, coagido no pensamento, com mais forte razão é absolutamente necessário que ele nasça, por arrombamento, do fortuito no mundo. O que é primeiro no pensamento é o arrombamento, a violência, é o inimigo, e nada supõe a Filosofia; tudo parte de uma misosofia. Não contemos com o pensamento para fundar a necessidade relativa do que ele pensa; contemos, ao contrário, com a contingência de um encontro, com aquilo que força a pensar, de uma paixão de pensar." (Deleuze, 1988, 230)

Mas apesar de o tempo deleuziano ser uma Multiplicidade, ele não é múltiplo, é Um, porém, sua unidade é virtual e é atualizada de maneiras diversas. Deleuze evoca, ao longo de sua obra, dois tipos de multiplicidade: a multiplicidade numérica, descontínua e atual do tempo estriado e a multiplicidade virtual e contínua, que corresponde à duração, ao tempo liso. Esta última é a mais relevante para compreendermos em que sentido Deleuze percebe o tempo como Multiplicidade. Em um trecho de Mil Platôs, Deleuze chama atenção para isto:

"(...) parece-nos que Bergson (muito mais ainda do que Husserl, ou mesmo Meinong e Russell) teve uma grande importância no desenvolvimento da teoria das multiplicidades. Pois desde o Ensaio sobre os Dados Imediatos, a duração é apresentada como um tipo de multiplicidade que se opõe à multiplicidade métrica ou de grandeza. É que a duração não é absolutamente o indivisível, mas o que não se divide sem mudar de natureza a cada divisão (...) Enquanto que numa 
multiplicidade como a extensão homogênea a divisão pode ser empurrada tão longe quanto se queira, sem que nada mude no objeto constante; ou então as grandezas podem variar sem outro efeito que o de um aumento ou uma diminuição do espaço que elas estriam. Bergson destacava pois "duas espécies bem diferentes de multiplicidade", uma qualitativa e de fusão, contínua; a outra, numérica e homogênea, discreta." (Deleuze, 1995, 191)

Como podemos ver, o tempo descrito por Deleuze é fundamentalmente paradoxal. Mas se ele o expressa assim é porque considera necessário que seja dessa forma, já que o tempo, em si, é paradoxal. Deleuze chama atenção para quatro paradoxos essenciais do tempo: o paradoxo do salto, de acordo com o qual não recompomos o passado com o presente, mas necessitamos dar um salto no tempo para nos instalarmos no elemento ontológico do passado; o paradoxo do Ser, que diz que passado e presente possuem naturezas diferentes, não sendo estágios diferentes de uma mesma natureza; o paradoxo da contemporaneidade, que chama atenção para o fato de que passado e presente coexistem, sendo indistinguíveis por antes e depois e; o paradoxo da repetição psíquica, que discrimina o fato de que, com cada presente, coexiste todo o passado e, portanto, o trabalho do espírito se faz por mudanças de níveis e não pela adjunção de elementos.

O paradoxo é instrumento fundamental para Deleuze, pois, se não inverte a direção única das coisas em sua sucessão sensata, o sentido tradicional do bom senso que orienta a flecha do tempo necessariamente a partir de um presente, ele abole o princípio da mão única que rege o próprio bom senso, afirmando diversas direções concomitantes, indo em múltiplos sentidos simultaneamente. O paradoxo coloca o presente, parâmetro da direção única do tempo, em questão, criando uma temporalidade centrífuga e dispersa. Afirma, ao mesmo tempo, múltiplas direções coexistentes, sabotando a recognição do Mesmo e seus postulados subjacentes; a identidade do sujeito reconhecedor e a constância do objeto reconhecido e de suas qualidades, que são os fundamentos do presente.

De todas as leituras do tempo realizadas por Deleuze, uma torna-se importante, na medida em que dialoga com a filosofia da Grécia clássica. Ele faz uma releitura singular de Cronos e de Aion, as duas faces simultâneas do tempo dos estóicos.

O Cronos imaginado por Deleuze é o presente, que existe em sua plenitude e sozinho e está em constante movimento. Ele se divide em um bom Cronos, que é o presente cronológico da superfície, e um mau Cronos, o devir-louco da profundidade, presente crônico. O Aion que ele concebe é a subdivisão do instante ao infinito, a inexistência de presente, sempre disperso em passado e futuro, que abre o tempo ao ilimitado. Pelbart define bem a diferença entre os dois tempos no seguinte trecho:

"Cronos é o tempo da medida ou da profundidade desmedida, ao passo que Aion é o da superfície. Cronos exprime a ação dos corpos, das qualidades corporais, das causas, Aion é o lugar dos acontecimentos 
incorporais, dos atributos, dos efeitos. Cronos é o domínio do limitado e infinito, Aion do finito e ilimitado. Cronos tem a forma circular, Aion é linha reta. Sensato ou tresloucado, Cronos é sempre da profundidade, localizado e localizável, assinalado e assinalável. Aion é radicalmente atópico, ou "transtópico" mas também, num certo sentido, condição de qualquer assinalamento temporal." (Pelbart, 2001, 72)

Essa releitura é tão inusitada que perguntamos a nós mesmos se Deleuze trabalhou com os mesmos estóicos que estamos acostumados a estudar. Mais uma vez, o filósofo questiona o pensamento dogmático e remexe as bases da filosofia tradicional, apostando na Diferença e no pensamento criador.

\section{Presente, passado e futuro}

Como já vimos, Borges refuta passado, presente e futuro, os três pilares do tempo que nega. Em Nova Refutação do Tempo, ele explicita que a negação do tempo é ambígua, podendo significar tanto a eternidade de Platão ou de Boécio, quanto os dilemas de Sexto Empírico, que nega o passado (que já foi), o futuro (que não é) e também o presente, já que este, paradoxalmente, não pode ser nem divisível (já que assim constaria de uma parte que foi e outra que não é), nem indivisível (pois assim estaria desvinculado do passado, seu princípio, e do futuro, seu fim, não podendo existir, pois não há meio onde não há início e fim). Intuímos em História da Eternidade, o apego borgesiano ao conceito de eternidade, que nos livraria do peso esmagador da sucessividade.

Apesar de propor um Tempo do Fora, ilimitado e não cronológico que pode lembrar a Eternidade almejada e historiada por Borges, a multiplicidade tipicamente deleuziana, alheia à necessidade de escolher uma verdade, permite conceber, ao mesmo tempo, imagens do presente, do passado e do futuro.

A questão do presente surge em Diferença e Repetição, quando Deleuze trata da repetição. De acordo com ele, não há um presente ou o presente como característica do tempo, mas apenas o presente em função do tipo de repetição que ocorre. Ele distingue, desta forma, dois tipos de repetição: a repetição material, em que instantes sucessivos são contraídos em um presente vivo; e a repetição espiritual, em que o passado puro é contraído como uma totalidade virtual coexistente. Dessas duas formas de repetição e do presente que cada uma implica, ele diz:

"Uma está nua, a outra está vestida; uma é das partes, a outra é do Todo; uma é de sucessão, a outra é de coexistência; uma é atual, a outra é virtual; uma é horizontal, a outra é vertical. O presente é sempre diferença contraída; mas, num caso, ele contrai os instantes indiferentes e, no outro caso, ele contrai, passando ao limite, um nível diferencial do todo que é, ele próprio, de descontração ou de contração." (Deleuze, 1988, 148) 
O presente aparece ao longo da obra do filósofo, constantemente como correlato a atual, em oposição a virtual. O privilégio cedido por Deleuze ao virtual, faz com que o presente apareça, muitas vezes, em segundo plano, mas Peter Pál Pelbart distingue, ainda assim, dois tipos de presente em Deleuze: o presente enquanto ponto genético do tempo, ou Cronogenético, e a cadeia de presentes que estabelece relações de sucessão e de simultaneidade, ou o presente Cronológico.

Os dois presentes podem ser vistos como duas faces do mesmo presente. O presente Cronogenético corresponde à contração enquanto processo de atualização e o Cronológico à contração já atualizada, no presente empírico. Toda a dificuldade do presente em Deleuze consiste no fato de que, ainda que ele seja o domínio próprio do atual, também pode ser lido a partir de sua gênese, mostrando seu avesso virtual que ele atualiza.

O passado, para Deleuze, não pode ser pensado como um antigo presente. O passado é transcendental, sendo anterior ao presente e condição da passagem dos presentes. Assim, por ser suposto por toda representação, não é passado representado. É a memória subrepresentativa, concebida como síntese passiva, transcendental, involuntária. A ela, Deleuze contrapõe a memória ativa, vitoriosa ao esquecimento, representativa. A memória passiva não se opõe ao esquecimento, já que penetra em seu elemento, mergulhando no em-si do passado, que jamais foi presente, o passado imemorial que fundamenta qualquer presente.

Desta maneira, o passado deleuziano não é uma dimensão empírica do tempo. Para melhor explicar esse fato, Deleuze recorre à memória erótica, já que o objeto para Eros é sempre virtual, jamais um antigo presente.

O futuro foi chamado por Deleuze de categoria régia. Ele quis fazer da repetição a categoria do futuro, ou seja, fazer do futuro o incondicionado; torná-lo objeto da repetição. Como destaca Pelbart, por um lado, o futuro deleuziano está intrinsecamente ligado ao instante, apresentando-se como o absolutamente novo; por outro lado, ele não pode ser separado do eterno retorno, em que as medidas usuais do tempo foram abolidas, restando um círculo vazio sem vetores temporais.

Em ambas as concepções, o futuro não é o que está à frente, mas o que está em qualquer lugar, arrastando constantemente para si o Todo virtual. Mesmo uma ação já realizada pode permanecer no futuro, por ser incompreensível para quem a realizou. O futuro está sempre fora, é virtual, como, por exemplo, a obra do artista que está sempre por vir. Na passagem abaixo, de $O$ Que é a Filosofia?, Deleuze aborda o futuro da seguinte maneira:

"Agir contra o passado, e assim sobre o presente, em favor (eu espero) de um porvir - mas o porvir não é um futuro da história, mesmo utópico, é o infinito Agora, o Nûn que Platão já distinguia de todo presente, o Intensivo ou o Intempestivo, não um instante, mas um devir. Não é ainda o que Foucault chamava de Atual? Mas como o 
conceito receberia agora $o$ nome de atual, enquanto Nietzsche 0 chamava de inatual? E que, para Foucault, o que conta é a diferença do presente e do atual. O novo, o interessante, é o atual. $O$ atual não é o que somos, mas antes o que nos tornamos, o que estamos nos tornando, isto é, o Outro, nosso devir-outro. O presente, ao contrário, é o que somos, e por isso mesmo, o que já deixamos de ser. Devemos distinguir não somente a parte do passado e a do presente, mas, mais profundamente, a do presente e a do atual. Não que o atual seja a prefiguração, mesmo utópica, de um porvir de nossa história, mas ele é o agora de nosso devir." (Deleuze, 1992, 144-145)

Observamos que a concepção de futuro em Deleuze permanece misteriosa, principalmente por sua negação enquanto presente por vir. De fato, presente, passado e futuro, misturam-se em um labirinto, superpondo-se em alguns momentos e afastando-se em outros, desafiando as tradicionais concepções do tempo como seqüencialidade linear.

\section{Conclusão}

Borges e Deleuze, estiveram, cada um a sua maneira, obcecados pela questão do tempo. O primeiro investiu em sua refutação; o segundo em uma concepção assustadoramente original, que está ligada essencialmente a sua maneira de filosofar, pondo em xeque as bases do pensamento ortodoxo, racional e unidirecional. Ambos, valendo-se de métodos distintos, questionaram nossa maneira tradicional de abordar o tempo, o que torna o paralelo entre as duas concepções verdadeiramente enriquecedor para a análise de um dos conceitos fundamentais de nossa cultura, bem como para a compreensão da obra dos dois autores. 


\section{REFERÊNCIAS BIBLIOGRÁFICAS}

PELBART, P. O Tempo Não-Reconcliliado. Imagens do Tempo em Deleuze. São Paulo, Perspectiva, 2004.

BORGES, J. L. "A Nova Refutação do Tempo." In: Outras Inquisições. Obras Completas, Vol. II, São Paulo, Globo, 1999.

. "História da Eternidade." In: História da Eternidade. São Paulo, Globo, 2001.

DELEUZE, G. "La Conception de la Différence chez Bergson." In: Les Études Bergsoniennes, vol IV, Paris, Albin Michel, 1956.

Diferença e Repetição. Rio de Janeiro, Graal, 1988.

. Mil Platôs. Rio de Janeiro, Editora 34, 1995. 1992.

e GUATTARI, F. O Que é a Filosofia? Rio de Janeiro, Editora 34, 